

\section{"I'm a police officer not a social worker or mental health nurse": Online discourses of exclusion and resistance regarding mental health related police work}

\section{ABSTRACT}

Despite estimates suggesting that around fifteen percent of UK police incidents involve people with a mental health concern, officers receive very little mental health training. The police have faced high-profile criticisms over their handling of mental health-related incidents, whilst the under-funding and fragmentation of UK mental health services has led to concerns that police officers are being forced to undertake a primary role in mental health care. At a time of austerity and widespread cuts to public services, it is important to explore how particular groups work to justify the parameters of their professional duties. This article therefore explores the discourses surrounding mental health problems on an online police discussion forum, highlighting two distinct ways in which mental health-related work is represented as being incompatible with policing. Firstly, mental health problems are delegitimised and conflated with 'scrounging', positioning individuals as undeserving of police time; secondly, mental health problems are reified and associated with violence and extreme behaviour, justifying the use of force by police officers and deflecting responsibility onto mental health services. Findings are consistent with previous research suggesting that mental health work is not perceived to be a valid part of the police role.

Key words: Stigma, Mental health difficulties, Policing, Discourse analysis, Internet discussion forums.

\section{INTRODUCTION}

Globally, the issue of policing and mental health has become a controversial topic in recent years; in the UK, high-profile incidents involving deaths in police custody (Morris, 2017), facedown restraint and Taser use (Robins, 2015), and alleged neglect by police officers (Morris, 2017) have received frequent media attention. Such incidents raise concerns about the conduct of police officers towards individuals experiencing mental health difficulties. Although there is 
a growing body of (mainly quantitative) literature regarding policing and mental health globally - particularly from the US - there has been a relative lack of empirical research concerning the UK context. This article aims to contribute to the qualitative literature by examining the discourses surrounding mental health problems on a UK-based internet police discussion forum. As this research pertains to police discourses concerning a strongly stigmatised group (those with mental health difficulties), it should also be relevant to those more broadly interested in matters of equality and diversity within UK police forces and those interested in the social construction of police identities.

\section{'Street corner psychiatry'}

Mental health related calls are a core feature of police work, with estimates suggesting that around fifteen percent of UK police incidents involve someone with a mental health concern (Bather, Fitzpatrick \& Rutherford, 2008). Section 136 of the Mental Health Act (1983) permits the police to detain and remove to a place of safety those suspected of being mentally unwell and in immediate need of care or control; the police are therefore often the initial contact and gateway to appropriate care for individuals experiencing mental health crises (Adebowale, 2013).

The under-funding and fragmentation of mental health services, following large-scale deinstitutionalisation, has forced the criminal justice system to undertake a community role of care towards those experiencing mental health problems (Rogers, 1990; Wolff, 2005). For example, a recent Care Quality Commission report (2013) highlighted a shortage of psychiatric inpatient beds and appropriate places of safety, leading to those in mental health crisis being detained frequently in police cells. Concerns that police officers are "filling in the gaps in mental health services" (House of Commons \& Home Affairs Committee, 2015, p. 33) have been raised, with one chief constable threatening to sue his local NHS trust over the lack of psychiatric beds (British Broadcasting Corporation, 2016).

The UK police have also faced high-profile criticisms over their handling of mental health-related incidents (e.g. Adebowale, 2013; Bradley, 2009; Mind, 2007). An Independent Commission on Mental Health and Policing investigation (Adebowale, 2013) cited discriminatory attitudes and 
behaviour amongst police officers, as well as the disproportionate use of force and a failure to provide adequate care in custody. At the time of conducting this study, UK police officers received very little training on mental health (Adebowale, 2013; Bradley, 2009; Cummins, 2007), with many officers feeling ill-equipped to handle mental health-related calls (Carey, 2001; McLean \& Marshall, 2010). Although the police have ostensibly undertaken the role of "street-corner psychiatrists" (Lamb, 2002, p. 1266), it has been argued that the social care aspect of police work is not highly valued in police training or culture (Paoline, 2003), with suggestions that psychiatric interventions are not viewed as real police work within police 'canteen culture' (Dunn \& Fahy, 1987; Cotton, 2004; Fry, O' Riordan \& Geanellos, 2002).

Previous research suggests that sharing experiences and storytelling are a crucial part of what officers do when they are not directly engaged in policing work (Van Hulst, 2013). These practices facilitate the socialisation of officers and provide cues for behaviour (Shearing and Ericson, 1991) that enable them to perform identity repair work (Waddington, 1999) and shape the values and beliefs associated with police work (Van Hulst, 2013). While previous ethnographic research has focused on interactions amongst colleagues sharing the same work spaces (e.g. office/canteen-based conversations), the present study explores police discussions regarding mental health difficulties within a virtual environment where individuals from different contexts exchange stories and engage in debates and banter regarding work-related matters. Such virtual environments provide an under-researched backstage space for 'naturally occurring' and anonymous storytelling and conversation.

\section{Discursive psychology and social categorisation}

This study took as its core assumption the socially-constructed nature of social categories. Its focus was therefore on how members use discourse to actively build up mentally-disordered identities and position mental health work in relation to policing. A number of recent studies have taken a discursive approach to the study of identity construction on discussion forums (e.g. Jowett, 2015; Giles \& Newbold, 2013). Consistent with the tradition of discursive psychology, category identities are viewed as interactional products constructed by, rather than described by language; 'attitudes' and discursive choices are engaged in justifying positions, implicitly countering alternatives, and in reproducing social inequalities (Potter \& Wetherell, 1987). The 
police are significant cultural producers of dramatized stories about urban space, crime, and mental illness (Linnemann \& Kurtz, 2014), with the "power to diagnose, classify, authorize and represent both individuals and the world" (Loader, in Linneman \& Kurtz, 2014, p. 341). Due to the importance of communicative practices in (re)producing definitions of social groups it is arguably important to attend to the interpretative practices used by such influential groups to define categories such as 'mental illness' (Boyd \& Kerr, 2016). The aims of this article are therefore to illustrate how discursive resources are used by forum members to both legitimise prejudice against individuals experiencing mental health difficulties and to position mental health-related work as incongruous with policing.

\section{METHODS}

Research site

Online discussion forums are virtual communication spaces structured by discussion threads; threads begin with a message containing information, questions, or requests, and are followed by further messages which discuss the topic of the first message. The police forum used in this study was selected due to its public accessibility, good search facilities, and its clear designation as a forum for members of the police force. The forum also had the highest number of users amongst the UK-based forums considered (listing 382,785 total posts and 36,672 users as of November 2014). This discussion forum was deemed an ideal site for relevant naturalistic interactions as it encourages users to engage in discussion regarding police-related topics and concerns. The benefits of naturalistic data are that they are not susceptible to influence by the analyst and allow participants' own voices and meanings to emerge (Potter, 2010). Conversations on such forums constitute a form of everyday interactions, with the added benefit that members' anonymity - and lack of accountability - may allow discussions that are unsayable in 'everyday' environments (e.g. overt expressions of prejudice). The internet can be a useful tool for researching distinct populations (Hine, 2000), and forums are arguably a useful platform for exploring professional culture and identity construction (Atherton, 2016); online environments also appear to provide a means through which people construct 'authentic' identities through online interactions (e.g. Burnett \& Buerkle, 2004; Horne \& Wiggins, 2009; 
Lamerichs, 2004).

\section{Forum users}

Information available on forum users consisted of usernames, number of posts, stated gender, and hobbies. Many different usernames were active across the threads; some users were particularly dominant, posting across multiple threads, while others only posted on single occasions. Given the open accessibility of the forum, it was impossible to confirm whether forum users were genuine police officers. However, it was common to see forum users explicitly presenting themselves as members of the public (e.g. by seeking advice on policing matters); such posting was not discouraged by members of the forum, thereby minimising any need to pose artificially as a police officer. Moreover, as Jowett (2015, p. 4) argues, "(f)or discourse analytic approaches, it is the interaction or textual representation of the research topic (which may include the construction of self and others) that is of interest rather than the 'real' identities of the people assumed to lie behind the text." From this perspective, social categories are viewed as 'interactional accomplishments' (Hepburn \& Wiggins, 2007, p. 3); thus, the concern of the analysis was with the production of shared social orders and the construction of authentic police identities through (for example) occupational narratives, displays of specialist knowledge and policing jargon etc.

\section{Data Selection}

The data consisted of seventy-five threads dating from 27/06/2009 to 25/03/2014 (the earliest possible date up until the point of data collection). Data collection involved searching the forum for threads relating to psychiatric disorder, using a 'title only' search (only threads with the key words included within the thread title were found), since an initial 'title and thread' search elicited a significant amount of irrelevant material. A list of search terms relating to mental illness was compiled, including medical (e.g. bipolar), police specific (e.g. Section 136) and slang (e.g. crazy, mad, etc.). To ensure no major terms had been overlooked, this list was derived from an online thesaurus and a previous study on commonly used labels for mental illness (Rose, 
Thornicroft, Pinfold \& Kassam, 2007). All threads were uploaded into NVivo 10 for analysis, retaining the original spelling and grammatical errors, emoticons and formatting.

\section{Ethics}

The ethical boundaries for collecting information from online public spaces are ambiguous and contested, mainly because the notion of the internet as a public space has been disputed (Hudson \& Bruckman, 2004; Nissenbaum, 2010; Townsend \& Wallace, 2016). I argue that the forum content used in the present study constitutes public data because the open-access nature of the forum means that users can reasonably expect to be observed by 'strangers' (British Psychological Society, 2010; 2013). For example, the BPS ethical guidelines for internet research state: "[w]here it is reasonable to argue that there is likely no perception and/or expectation of privacy (or where scientific/social value and/or research validity considerations are deemed to justify undisclosed observation), use of research data without gaining valid consent may be justifiable" (BPS, 2013, p. 8). However, although the terms and conditions explain that the forum is not a secure platform and that posts are publicly accessible and relatively permanent, users may not consider the possibility of its potential use by researchers. Informed consent therefore constituted an ethical dilemma for the present study as participants were not told their data were being used for research purposes. However, obtaining permission from individual users would have been difficult, because of the unstable and shifting membership of such groups and the critical nature of the research. It has been argued that certain forms of critical research may be exempt from seeking informed consent, given the potential indirect censorship that could be imposed by social media research ethics on critical research (Jowett, 2015; Townsend \& Wallace, 2016); the study was therefore conducted in the belief that the forum was highly worthy of analysis. Jowett (2015), for example, suggests that internet discussion forums are particularly useful for critical psychologists because they provide access to interactional discourses concerning power, identity and prejudice, which would otherwise be difficult to explore. To ensure the anonymity of participants, usernames were replaced with pseudonyms and one quotation was omitted because it was found to be traceable to its original source via internet searching. The likelihood of the research causing harm to 
participants was therefore extremely low, given the minimal threat to participant confidentiality.

\section{Analysis}

The analysis essentially followed Wiggins's (2017) broad guidelines for Discursive Psychological (DP) analysis (attending to the What, How, and When of talk). Threads were initially read and reread to capture emerging patterns in the depictions of mental health problems and policing and the kinds of social actions being accomplished within these accounts. A closer reading of threads then allowed the identification of discursive resources (e.g. narratives, lexical choices, membership categorisation, etc) and interpretative repertoires - culturally familiar arguments comprised from recognisable themes and common tropes (Potter \& Wetherell, 1987). This version of DP attended to both broader themes across forum posts and threads and to the more sequential aspects of discourse within the threads (i.e. exploring how and with what effect discursive resources are deployed). In accounting for the dominant and recurring representations of mental illness, as well as the action orientation and local pragmatism of talk (Edwards \& Potter, 1992) (e.g. ways of deflecting accusations of prejudice, allocating blame, etc.), this analysis resembles Wetherell's (1998) synthesis of DP and Critical Discourse Analysis.

\section{FINDINGS}

This section presents the analysis of forum discussions regarding mental illness and mental health related police work. It will show how two broad interpretative repertoires are used to both justify negative 'attitudes' towards individuals with mental health problems and to position mental health-related work as being incongruous with police work and its aims. The first repertoire illustrates how scepticism towards people claiming disability benefits on the grounds of poor mental health is justified through the building up of unachievable category incumbency criteria (Jayyusi, 1984) ${ }^{1}$ for 'genuine' mental illness. Work relating to such

\footnotetext{
${ }^{1}$ Category incumbency (Jayyusi, 1984) refers to a person's rights to claim membership of a certain category; category incumbency criteria refer to a set of criteria by which an individual's category membership can be judged.
} 
individuals (who are depicted as attention seekers or 'scroungers') is presented as a waste of police time and a non-valid aspect of their role. By contrast, the second repertoire concerns the depiction of those whose status as mentally ill is unquestioned by members. Such individuals are constructed as being either too severely unwell to be handled by police officers, or as so severely disordered that they need to be forcefully restrained. In both sections, therefore, mental health-related work is depicted as being incompatible with police work, unless there is a requirement for physical restraint.

\section{Spongers and Scroungers}

This section focuses on the depiction of alleged 'non-genuine' expressions of mental ill health within a single forum thread entitled: 'Increase in people threatening to commit suicide' (this was the longest thread analysed, extending over a three-month period with 96 posts and 16 contributing users). The conflation of mental health and moral deviancy was commonly seen throughout the dataset, but this thread was selected as a good example of the interactional coconstruction of 'non-genuine' mental health difficulties between contributors. Frequent scepticism regarding the authenticity of mental distress and associated behaviours (e.g. selfharm and claiming benefits) is displayed, along with a concern that police time is being wasted on non-deserving individuals. Furthermore, individuals depicted as genuinely mentally unwell are presented in unflattering terms, and incidents involving such people are excluded as valid forms of police work.

The initiating post (Extract 1) explicitly connects increased suicide threats (involving police callouts) to the increased difficulty of claiming Disability Living Allowance (DLA), thereby equating expressions of mental distress to benefit 'scrounging'. Responses to Extract 1 explicitly criticise such 'scroungers', building up detailed depictions of non-genuine claimants.

\section{Extract 01}

Tackleberry Posted 14 July 2011

1 I dont know about anyone else, but over last 3/4 months I've seen a massive 2 increase in the number of jobs that $i$ and colleagues have gone to where the IP has 3 threatened to committ suicide, where its ended up with them either being detained 
4136 or going to get assessed voluntarily. Now call me cynical if you want, but what

5 a coincidence its happening when the governments osterity measures involve 6 getting people off DLA. Ive also been informed by a friend, who deals with this 7 stuff, that to claim DLA on mental health grounds you need an admission within 8 the previous 12 months. It really is a coincidence. Again the great unwashed are $9 \quad$ putting more strain on resources, when they've contributed nothing, just to work 10 the system. It really does make me sick!!

Drawing upon occupational jargon, Tackleberry claims that injured persons (IPs) have threatened suicide in order to be detained under Section 136 of the Mental Health Act, enabling their admission to a psychiatric ward (line 7) in order to claim DLA. This conflation of mental health problems with unemployment and deviance is consistent with findings from previous research (e.g. Mathieu, 1993; Wahl, 1995), suggesting that mental illness challenges the protestant work ethics and Western capitalist ideals of market participation and independence (Olstead, 2002).

Whilst overtly attacking people who make illegitimate claims for DLA, those with 'genuine' mental health problems are also being implicitly linked with the claiming of unemployment benefits. They cannot be exempted from the membership categorisation device (MCD) (Sacks, 1992) "great unwashed", because in this extract the device can be seen to encompass all recipients of unemployment benefits. MCDs are superordinate collections of individual category memberships with specific rules of application; Sacks' consistency rule suggests that when two categories are used and are ostensibly part of the same device, they should be treated as such (Sacks, 1992, p. 239). The predicates of putting a "strain on resources" and "contributing nothing" that are applied to the device "great unwashed", can be heard to apply to both 'genuine' and 'non-genuine' DLA recipients. Only the final statement "just to work the system" suggests a distinction within the device between those who deliberately exploit the system and those who genuinely require benefits. This polarised 'us vs. them' dichotomy (Van Dijk, 1995), whereby those who "have contributed nothing" (line 8) are taking resources from the contributors, reflects a common narrative within the forum whereby the police are constructed as victims of morally depraved groups such as 'scroungers'. The extract implies that the police are one of the "resources" being "strained" (line 8) as they have seen a "massive increase" in this type of job (line 1-2) and are thus victims of the "great unwashed". 
In Extract 1, the group being explicitly criticised are the 'non-genuine'. This distinction between the genuinely mentally disordered and those who "work the system" is then taken up by other forum members, with the word 'genuine' occurring thirty-five times within this thread alone. The 'genuinely' mentally ill are usually constructed as deserving help, as illustrated in the following extract: -

\section{Extract 2}

Officer Mahoney Posted 17 July 2011

1 but $i$ dont think they will ever sort out the hardcore scroungers mental health is

2 just the latest loophole they have found to get round some hard graft and if the

3 powers that be do ever manage to close it the genuine ones will suffer they always

4 do.

Although notions of what constitute 'genuineness' are generally vague and undefined in the thread, Officer Mahoney implies that suffering is a consistent feature of 'genuine' mental ill health, since the 'genuine' are presented as perpetual victims (line 3). This implies a contrast between 'genuine' and 'non-genuine' that is based on helplessness, indicating that anyone who does not suffer is unlikely to be genuine. The association of helplessness with the category 'genuine mental illness' is one of the few times in the thread where incumbency criteria for 'genuine' mental illness are explicitly suggested. By contrast, other posts - as will be illustrated in extracts $3 \& 4$ - build up numerous exclusion criteria for 'genuine mental illness', thus defining 'genuine' mental illness in negative terms. Mental illness could be considered to have 'weak category incumbency' (i.e. it is impossible to 'prove' and is not clearly visible), making it complex and difficult for outsiders to apply (Potter, 1996). In this thread, the diffuse criteria for 'genuine' mental health problems is exploited as a means to reject potential category members; the diffuseness also arguably make it easier for members to define this category in negative terms (i.e. by referring to what does not constitute genuineness), a tendency which has been noted in other studies on identity (e.g. Clarke \& Smith, 2014; Dickerson, 2000, Greenland \& TaulkeJohnson, 2016).

The following narrative illustrates the tendency for non-genuine DLA claimants to be described as extravagant consumers (six posts featured this claim), building up exclusion criteria for 
'genuine' mental illness: consumption and leisure activities are suggested to indicate immorality and non-genuineness.

\section{Extract 3}

Tackleberry Posted 16 July 2011

$1 \quad$ I agree theyre not all spongers, but a lot are and a lot could do some kind of work.

$2 \quad$ For instance; went to a 42 year old female house 6 weeks ago who had threatened

3 suicide. When asked if she was on DLA she stated she was. When asked why, she

$4 \quad$ stated she had a scar up her knee after being attacked 5 years ago. When asked

5 what it stopped her doing, as it obviously didn't stop her watching tv, eating pizza,

6 smoking and drinking herself into oblivion on bottles of cider. She then got on the

7 offensive. I suppoose it did stop her doing stuff as it had obviusly stopped her

8 hoovering, polishing, tidying up and having a wash, the scruff bag. I wouldn't be

9 surprised if we'll soon be paying for someone to go in and clean for her soon. Get

10 em in the institutions ASAP, AT LEAST IT WILL STOP THEM WASTING OUR MONEY

Beginning with a disclaimer (Van Dijk, 1995, p. 179) that acknowledges the existence of genuine claimants ("they're not all spongers, but...") - thus demonstrating the reasonable stance of the user - Extract 3 then describes a person who is cited as an example of a 'sponger' (line 1). While criteria for genuineness remain undefined, the narrative builds up exclusion criteria that demonstrate how this individual fails to qualify as 'genuine'. For example, eating takeaways, drinking, smoking, and poor personal hygiene are taken to imply immorality and inauthenticity. Extreme Case Formulations (Pomerantz, 1986) are used to highlight moral depravity ("drinking herself into oblivion"), while the contrasting minimal and global formulation (Potter, 1996) - "a scar up her knee" - undermines the legitimacy of the subject's disability. The focus only on this physical fact also discounts the possibility of psychological distress as constitutive of a 'genuine' disability, which is therefore assumed to be clearly visible; self-neglect is thus ascribed to moral deviancy rather than indicating possible illness.

Sarcasm is used to imply that this woman could clean but is lazy and self-destructive, as suggested by the activities of watching TV, drinking and smoking (line 6). The implication in this instance is that disability is genuine only when individuals are incapable of performing 'normal' moral activities (as well as consumerist activities). The 'genuine' are distinguished by their inability to clean (as opposed to laziness) and their blamelessness (as opposed to self- 
destructiveness). Like Extract 2, this constructs a 'passive patient' stereotype of mental illness - helpless, disempowered and childlike, without responsibility and independence (Olstead, 2002). Furthermore, the reference to institutionalisation (line 10) conflates the 'genuine' with the deviant 'non-genuine' category, since presumably this suggestion implies that 'genuine' individuals should also be institutionalised. This also insinuates that those experiencing 'genuine' mental health problems are not valid recipients of police attention.

Further on in the thread, a debate develops between a self-identified non-police member with mental health issues (Eevee) and other (alleged) police members regarding the offensive tone of the thread. Eevee works up his/her own 'genuineness' by listing several mental health diagnoses and providing a detailed history of psychiatric treatment and suicide attempts. S/he also provides a lengthy explanation as to why people self-harm or attempt suicide. Despite this, responses to this post are mostly hostile, constructing Eevee as a 'non-genuine' case (for example, the 'genuine' nature of Eevee's disability is challenged on the basis of his/her ability to write cogently). Extract 4 follows a post in which Eevee suggests that drug/alcohol addiction is a mental health issue deserving of sympathy:

Extract 4

Jones Posted on 22 October 2011

1 Firstly, alcohol and drug abuse/addiction is not an illness or disability. It's self

2 inflicted. Besides of I was disabled and there was a possible cure I'd jump at the

3 chance of treatment whereas most junkies and piss cans don't want help (they're

$4 \quad$ offered help every time they're arrested AND tens of other times in between)

$5 \quad Y$ You've gone on about ploughing money into other areas other than police to tackle

6 these issues. This I agree with. I'm a police officer not a social worker or mental

7 health nurse nor do I want to be. So next time you have the urge to pretend to kill

8 yourself don't call us call someone who can help. Because while we're pampering

9 to your selfish needs there are others who really do need our help who aren't

10 getting it. 
As in extract 3, characteristics denoting authentic mental illness are not specified; however, reference is made to the theoretical existence of genuine individuals ("there are others who really do need our help..."). By contrast, Jones labels Eevee as "selfish" and states that s/he is wasting police time. Drug/alcohol addiction is also excluded from the 'genuine' category as it is portrayed as self-inflicted (line 1), implying that the possession of agency in relation to one's health is a further excluded characteristic. The number of exclusion criteria within these extracts arguably illustrate that defining 'genuine' mental ill health in negative terms (i.e. by virtue of what it is not) facilitates the maximum exclusion of individuals from the 'genuine' category.

In extract 4, Jones also argues conflictingly that addicts are offered massive assistance whilst at the same time agreeing that increased funding needs to be allocated "into other areas other than police to tackle these issues" (lines 5-6) due to the lack of available help. Criticisms of mental health services were prevalent in several threads, alongside common complaints that the police are having to conduct work beyond their remit (i.e. mental health work) (lines 6-7). This repertoire will be explored further in the following section.

\section{Excluding mental health work from policing through reification}

Numerous threads addressed alleged police misconduct towards those with mental health difficulties. Whilst some also concerned possible discrimination by society in general, for instance thread entitled 'sterilisation clinic for addicts' and 'is it wrong to jokily call someone mental?', this section will focus on threads involving perceived police violations. In contrast with the previous repertoire, those with mental health problems were depicted as being either too severely unwell to be handled by police officers, or as so severely disordered that forceful restraint is necessary. The inadequacies of mental health services were often blamed for bringing the police into contact with the mentally ill, who were often depicted as violent and in need of forceful restraint. The police tended to be positioned as victims who were having to perform work beyond their remit or being criticised unfairly for performing their rightful duties (e.g. Taser use and face-down restraint). Extract 5 (from the thread 'Police Taser use on mentally ill slammed') illustrates how Taser use is justified through an emphasis on the violent potential 
of mentally disordered individuals, with the blame attributed to inadequate mental health services and a lack of resources. The thread begins with an account of a report by mental health charity MIND which allegedly criticises the use of Tasers by the police on the mentally ill and calls for less harmful alternatives. The ensuing debate (involving 23 posts and 12 contributors) is defensive, comprising justifications of Taser use and the rejection of alternative, non-harmful forms of restraint.

\section{Extract 5}

Sgt Proctor Posted 29 December 2012

1 I have to say im a little dubious when i hear about means to restrain that don't

2 cause any harm at all. I have dealt with people for whom pain is irrelevant and 3 mechanical restraint only risks damage to them as they are still using all means $4 \quad$ they have to escape. It would be great if it does exist. We could be better trained. 5 But that costs money and with physical interactions over Taser require more 6 training and more practice and higher standards. We dont have the time or 7 money any more.

8 What would be better is if the mental health provision of the UK was made more 9 effective because at the moment, from my perspective is a total shambles. I have 10 been asked on many occasions to detain someone at a custody suite, rather than 11 our local MH Hospital because the patients like our staff better and want to get 12 help. This seems to suit the $\mathrm{MH}$ hospital who will reject people at the drop of a 13 hat and can only deal with maybe one or two people a day. Then we get slated 14 for not using the hospital for MH patients. And of course the number of suicidal, 15 dangerous, unbalanced people allowed to leave for the day or who just walk out 16 the door is endless and daily. Leading to confrontations with police who have 17 little option left other than taser. I suppose we could call out the hospital staff who are trained to deal with them. (i make little joke).

This extract functions to defend the police against criticism by shifting the blame onto mental health services and justifying the excessive use of force. In contrast to the previous section, the mentally ill are characterised as having 'real' problems requiring specialised medical care that is not being provided. The description of "people for whom pain is irrelevant" (line 2) - an Extreme Case Formulation (Pomerantz, 1986) depicts a divergent, exceptional and non-human category, beyond control and reason. Lines 12-15 highlight the hazardous nature of those who are mentally unwell ("suicidal, dangerous, unbalanced") and their lack of integration within the community. 
Non-violent restraint is constructed as naïve and idealistic, and as an extreme case (not causing "any harm [emphasis added] at all"). Wetherell, Stiven and Potter (1987) referred to this rhetorical technique - where a principle is cited but then immediately undermined by the impracticalities of upholding the principle - as the principle/ practice dichotomy. Another example of this is the (weak) admission that the police "could [emphasis added] be better trained", immediately qualified by a statement about lack of resources - "we don't have the time or money..."; ending this statement with "any more" frames this as a purely financial issue - in other words, it is not motivated by prejudice against individuals with a mental health problem. This serves to deflect potential accusations of prejudice and illustrates how 'practical talk' can function to legitimatise existing social inequities (Augoustinos \& Every, 2007).

Accusations of police prejudice are also deflected by reframing the issue as a problem for mental health services by claiming that patients actually prefer police to mental health staff (lines 7-9). The denigration of mental health services occurred frequently in the threads, and Extreme Case Formulation (Pomerantz, 1986) is used again here to convey the irresponsible and uncaring attitude of mental health staff, through descriptions referring to the "endless and daily" discharge and rejection of "suicidal, dangerous, unbalanced people.....at the drop of a hat". Police contact with the mentally unwell is thereby formulated as an 'end of the line' intervention - a consequence of failures by mental health services, where individuals have reached the peak of distress, necessitating the use of violent force. Managing violence is thus constructed as an indisputable aspect of the police role.

Whilst Extract 5 depicts mentally unwell individuals as requiring care, Extract 6, by contrast, constructs an account of a violent 'maniac' who is undeserving of sympathy. This thread entitled 'Maniac armed with shears is Tasered' - begins by recounting a news report describing how police used Tasers to disarm a 'maniac' carrying shears whilst trespassing on private property. Although the police are not blamed for their conduct in this instance, the thread largely focuses once again on criticisms of the police regarding their behaviour towards the mentally unwell.

\section{Extract 6}

CaptainHarris Posted 22 November 2013

1 Excellent work. I'm surprised, however, that the usual bleeding heart do-gooders 
2 aren't gathered in conference collectively on their bean-bags to bleat about the

3 fact he was Tasered atop of the car and might have fallen and hurt himself. Makes

4 a nice change that the Police, in this case, seem to have been allowed to do their

5 job and take decisive action to negate a clear threat without all the usual

6 nonsense and severely mis-placed sympathy incidents like this seem to attract.

$7 \quad$ Well done to all those involved...

The 'maniac' in the thread title is presented as a violent 'horror' caricature, devoid of personal history, status or individual characteristics. This is consistent with sensationalised media reporting of mental illness and violence (Olstead, 2002). Both the invocation of the 'maniac' caricature and the frightening depiction (maniac with shears) permits dehumanisation, allowing normal rights to sympathy to be deemed "severely mis-placed" (line 6). Taser use is constructed as part of the police role (line 5) and as taking "decisive action", again defending the rightful and necessary use of violent force by the police against "maniacs" and dismissing potential criticism from the "bleeding heart do-gooders".

\section{DISCUSSION}

This study explored the constructions of mental health difficulties and mental health related work within the specific context of a peer-based discussion forum for police officers. Most notably, the findings highlight two distinct and seemingly contradictory repertoires which position mental health work as incongruous with the policing role, prompting questions as to which aspects of mental health would be considered valid police work. Both repertoires also serve to reinforce broader negative stereotypes surrounding mental health problems.

Firstly, those displaying mental health difficulties are rejected on moral grounds, whereby mental health difficulties are conflated with deviance and dishonesty. The unattainable incumbency criteria for 'genuine' mental illness recasts most individuals claiming to suffer from mental distress and disorder as deviant and unworthy of police attention, whilst even 'genuine' mental illness is conflated with deviancy and unemployment through the description of the 'great unwashed' MCD (Sacks, 1992). The moral concerns around 'scrounging', dishonesty and deviancy are consistent with research demonstrating the 
conflation of mental illness with other 'undesirable' categories (e.g. Mathieu, 1993; Olstead, 2002; Wahl, 1995).

The discursive manoeuvring of the line between mental illness and moral deviance is perhaps especially relevant at a time when governments justify welfare austerity by recasting stigma as deviance (Scambler, 2009), and may reflect current trends towards the criminalisation of poverty (Wacquant, 2001). This tendency could be particularly problematic for police officers, amongst whom the disciplining of moral deviance may be perceived as a key aspect of their role. These findings suggest that anti-stigma initiatives aimed at the police (and other groups) may also need to target ideas surrounding the wider forms of deviance with which mental health problems are conflated.

In the second repertoire, mental health callouts are instead rejected on the grounds of inappropriateness, whereby the police are argued to lack the expertise required to deal with a group of people constructed as irrational, unpredictable and dangerous. In contrast with the first repertoire mental health problems were reified, with the suggestion of an essential relationship between mental illness and violence. Those experiencing mental health difficulties were sometimes presented in dehumanising and one-dimensional ways, suggesting a 'sub-human group' who exist outside 'the usual fabric of society' (Olstead, 2002, p. 625). Stereotypes concerning violence and instability were common, reflecting the association between mental illness and violence found in public opinion (e.g. Schomerus et al., 2012) and in media representations (e.g. Kesic, Ducat \& Thomas, 2012; Olstead, 2002; Wahl, 1995). Depictions of extreme and violent behaviour were used to both justify police conduct (e.g. forceful restraint, Taser use, etc.) and to deflect responsibility from the police onto the mental health professionals trained to handle this category of people. Aspects of mental health work more closely resembling law enforcement (e.g. physical restraint, Taser use, etc.) were justified as legitimate police work, albeit an aspect exacerbated by the alleged failings of mental health services. By contrast, mental health related police work was portrayed as the result of a failing mental health system.

In practical terms, this analysis highlights the difficulties in defining police responsibilities towards those experiencing mental distress and disorder. In a context where deinstitutionalisation has occurred without sufficient community support and where models 
of policing increasingly emphasise care in the community, this resistance towards the amount of mental health work involved in policing seems unsurprising. It highlights the need for the overlapping nature of police and mental health services work to be acknowledged, as well as an organisation wide acceptance that mental health response is a core police duty (Sced, 2006). This may help to facilitate more integrated service responses.

However, disagreement has continued to characterise debates regarding the appropriate scope of police roles (e.g. see Millie, 2014). It has been suggested that the police often experience ambiguity over their roles, and that whilst they are expected to perform multiple responsibilities, only the role of law enforcement is rewarded within the organisation (Paoline, 2003); the privileging of crime-fighting was also apparent within forum discussions. This stance also extends beyond the police organisation; for example, in a 2011 speech, then Home Secretary Theresa May asserted that "We need (the police) to be the tough, nononsense crime fighters they signed up to be." With such discourses remaining prevalent despite the organisational and societal changes affecting police work, it seems likely that disagreements will continue regarding the role of police officers in performing mental health related work.

\section{Study limitations}

The first point to note is that these findings are based on content expressed within the specific context of an online discussion forum; it cannot be assumed that the prevalence of stigmatising discourses on the forum are reflected within wider police culture. Online forum participation is often unevenly distributed, with a core group of participants contributing most actively to the posts, running the forum and managing the discussions (Butler, Sproull, Kiesler \& Kraut, 2002). This was apparent within the forum as some of the chosen extracts came from highly prevalent posters who seemed particularly influential in guiding both topic choice and discussion. Further research is needed to explore police discourses surrounding mental health in spaces where occupational status can be verified and a wide variety of sources can be ensured, for instance through institutional ethnographies. 


\section{REFERENCES}

Adebowale, V. (2013). Independent Commission on Mental Health and Policing Report. London: House of Lords.

Atherton, S. (2012). Cops and Bloggers: Exploring the presence of police culture on the web. Internet Journal of Criminology, 1-28.

Augoustinos, M., \& Every, D. (2007). Language of "Race" and Prejudice: A Discourse of Denial, Reasonability and Liberal-Practical Politics. Journal of Language and Social Psychology, 26(2), 123-141.

Bather, B., Fitzpatrick, R. \& Rutherford, M. (2008). Briefing 36: The Police and Mental Health. London: Sainsbury Centre for Mental Health.

Boyd, J. \& Kerr, T. (2016). Policing 'Vancouver's Mental Health Crisis': A Critical Discourse Analysis, Critical Public Health, 26(4), 418-433.

Bradley, K. (2009). The Bradley Report. London: Department of Health.

British Broadcasting Corporation (2016). Police threaten legal action over lack of mental health beds. [online] available from http://www.bbc.co.uk/news/uk-england-devon37583441 [7 October 2016].

British Psychological Society. (2010). Code of Human Research Ethics. Leicester: BPS.

British Psychological Society. (2013). Ethics Guidelines for Internet-mediated Research. Leicester: BPS.

Burnett, G., \& Buerkle, H. (2004). Information exchange in virtual communities: A comparative study. Journal of Computer-Mediated Communication, 9(2).

Butler, B., Sproull, L., Kiesler, S., \& Kraut, R. (2002). Community effort in online groups: Who does the work and why. Leadership at a distance: Research in technologically supported work, 171-194.

Care Quality Commission (2013). A Criminal Use of Police Cells? The Use of Police Custody as a Place of Safety for People with Mental Health Needs. London: Care Quality Commission.

Carey, S. (2001). Police officers' knowledge of, and attitudes to mental illness in southwest Scotland. Scottish Medical Journal, 46, 41-42. 
Clarke, V., \& Smith, M. (2014). "Not Hiding, Not Shouting, Just Me": Gay men negotiate their visual identities. Journal of Homosexuality, 62(1), 4-32.

Cotton, D., \& Coleman, T. (2010). Understanding Mental Illness: A review and recommendations for police education and training in Canada. Toronto: Canadian Alliance on Mental Illness and Mental Health.

Cummins, I. (2007). Boats against the current: vulnerable adults in police custody. The Journal of Adult Protection, 9(1), 15-24.

Dickerson, P. (2000). 'But I'm different to them': Constructing contrasts between self and others in talk-in-interaction. British Journal of Social Psychology, 39, 381-398.

Dunn, J., \& Fahy, T. A. (1987): Section 136 and the police. Bulletin of the Royal College of Psychiatry, 11, 224-225.

Edwards, D., \& Potter, J. (1992). Discursive psychology ( $8^{\text {th }}$ ed.). London: Sage.

Fry, A., O' Riordan, D., \& Geanellos, R. (2002). Social control agents or front-line carers for people with mental health problems: police and mental health services in Sydney, Australia. Health \& social care in the community, 10(4), 277-286.

Giles, D., \& Newbold, J. (2013). 'Is this normal?' The role of category predicates in constructing mental illness online. Journal of Computer-Mediated Communication, 18(4), 476-490.

Greenland, K., \& Taulke-Johnson, R. (2017). Gay men's identity work and the social construction of discrimination. Psychology \& Sexuality, 8(1-2), 81-95.

Hepburn, A., \& Wiggins, S. (Eds.). (2007). Discursive research in practice: New approaches to psychology and interaction. Cambridge: Cambridge University Press.

Hine, C. (2000). Virtual Ethnography. London: SAGE Publications Ltd.

Horne, J., \& Wiggins, S. (2009). Doing being 'on the edge': managing the dilemma of being authentically suicidal in an online forum. Sociology of Health \& IIIness, 31(2), 170-184.

Hudson, J., \& Bruckman, A. (2004). Go away: Participant objections to being studied and the ethics of chatroom research. Information Society, 20(2), 127-139.

Jayyusi, L. (1984). Categories and the moral order. London: Routledge. 
Jowett, A. (2015). A case for using online discussion forums in critical psychological research. Qualitative Research in Psychology, 12(3), 287-297.

Kesic, D., Ducat, L., \& Thomas, S. (2012). Using force: Australian newspaper depictions of contacts between the police and persons experiencing mental illness. Australian psychologist, $47(4), 213-223$.

Lamb, M., Weinberger, L., \& Gross, B. (2004). Mentally ill persons in the criminal justice system: Some perspectives. Psychiatric Quarterly, 75(2), 107-126.

Lamerichs, J. (2004) Discourses of support: exploring online discussions on depression, Unpublished Doctoral Dissertation. University of Wageningen, Netherlands.

Linnemann, T., \& Kurtz, D. (2014). Beyond the ghetto: Police power, methamphetamine and the rural war on drugs. Critical Criminology, 22(3), 339-355.

Mathieu, A. (1993). The medicalization of homelessness and the theatre of repression. Medical Anthropology Quarterly, 7(2), 170-184.

May, T. (2011, 16 August). Theresa May speech in full. Retrieved from http://www.politics.co.uk/comment-analysis/2011/10/04/theresa-may-speech-in-full.

Mclean, N., \& Marshall, L. (2010). A front-line police perspective of mental health issues and services. Criminal behaviour and mental health, 20(1), 62-71.

Millie, A. (2014). The case for a narrower focus to policing. Public Safety Leadership Research Focus, 'The Great Debate: How wide or narrow should the police's remit be?', 2(4), 1-4.

MIND (2007). Another assault: Mind's campaign for equal access to justice for people with mental health problems. London: MIND.

Morris, Steven (2017). Thomas Orchard death police cleared of manslaughter. [online] available from https://www.theguardian.com/uk-news/2017/mar/14/thomas-orcharddeath-police-cleared-of-manslaughter [14 March 2017].

Morris, Steven (2017). Police chief lied about man with mental health issues who died in cell. [online] available from https://www.theguardian.com/society/2017/sep/05/police-chieflied-about-man-with-mental-health-issues-who-died-in-cell-hearing-james-herbert. September 2017]. 
Nissenbaum, H. (2010). Privacy in context: Technology, policy, and the integrity of social life. Stanford: Stanford University Press.

Olstead, R. (2002). Contesting the text: Canadian media depictions of the conflation of mental illness and criminality, Sociology of Health and IIIness, 24(5), 621-643.

Paoline, E. (2003). Taking stock: Toward a richer understanding of police culture. Journal of Criminal Justice, 31(3), 199-214.

Pomerantz, A. (1986). Extreme case formulations: A way of legitimizing claims. Human studies, 9(2), 219-229.

Potter, J., \& Wetherell, M. (1987). Discourse and social psychology: Beyond attitudes and behaviour. London: Sage.

Potter, J. (1996). Representing reality: Discourse, rhetoric and social construction. London: Sage.

Potter, J. (2010). Contemporary discursive psychology: Issues, prospects, and Corcoran's awkward ontology. British Journal of Social Psychology, 49(4), 657-678.

Robins, J. (2015). Majority of suspects tasered by police are mentally ill figures show. [online] available from http://www.independent.co.uk/news/uk/crime/majority-of-suspectstasered-by-police-are-mentally-ill-figures-show-a6786996.html [26 December 2015].

Rogers, A. (1990). Policing Mental Disorder: Controversies, Myths and Realities. Social Policy and Administration, 24.

Rose, D., Thornicroft, G., Pinfold, V., \& Kassam, A. (2007). 250 labels used to stigmatise people with mental illness. BMC Health Services Research, 7, 97.

Sacks, H. (1992). Lectures on conversation. 2 vols. Edited by Gail Jefferson with introductions by Emanuel A. Schegloff. Oxford: Blackwell

Shearing, C. D., \& Ericson, R. V. (1991). Culture as figurative action. British Journal of Sociology, 481-506.

Scambler, G. (2009). Health-related stigma. Sociology of Health \& IIIness, 31(3), 441-455.

Sced, M. (2006). Mental illness in the community: The role of police. Australasian Centre for Policing Research. 
Schomerus, G., Schwahn, C., Holzinger, A., Corrigan, P., Grabe, H. J., Carta, M. \& Angermeyer, M. (2012). Evolution of public attitudes about mental illness: a systematic review and metaanalysis. Acta Psychiatrica Scandinavica, 125(6), 440-452.

Townsend, L., \& Wallace, C. (2016). Social media research: A guide to ethics. University of Aberdeen.

Van Dijk, T. A. (1995). Discourse semantics and ideology. Discourse \& Society, 6(2), 243-289.

Van Hulst, M. (2013). Storytelling at the police station: the canteen culture revisited. British Journal of Criminology, 53(4), 624-642.

Wacquant, L. (2001). The penalisation of poverty and the rise of neo-liberalism. European Journal on Criminal Policy and Research, 9(4), 401-412.

Waddington, P. A. (1999). Police (canteen) sub-culture. An appreciation. British Journal of Criminology, 39(2), 287-309.

Wahl, O. (1995). Media madness: Public images of mental illness. New Brunswick, NJ: Rutgers University Press.

Wetherell, M., Stiven, H., \& Potter, J. (1987). Unequal egalitarianism: A preliminary study of discourses concerning gender and employment opportunities. British Journal of Social Psychology, 26(1), 59-71.

Wetherell, M. (1998). Positioning and interpretative repertoires: Conversation analysis and post-structuralism in dialogue. Discourse \& Society, 9(3), 387-412.

Wiggins, S. (2017). Discursive psychology: Theory, method and applications. London: Sage.

Wolff, N. (2005). Community reintegration of prisoners with mental illness: A social investment perspective. International Journal of Law and Psychiatry, 28, 43-58. 